\title{
MORPHOLOGICAL CHARACTERIZATION OF GANODERMA SPECIES FROM MURREE HILLS OF PAKISTAN
}

Fakhar-ud-Din, Tariq Mukhtar

Department of Plant Pathology, Pir Mehr Ali Shah Arid Agriculture University, Rawalpindi, Pakistan.

ART I CLE INFO

\section{Article history}

Received: 13 $3^{\text {th }}$ May, 2019

Revised: 29th July, 2019

Accepted: 28th August, 2019

Keywords

Ganoderma

Cultural characterization

Morphology

Pileus

Forest trees

\section{A B S T R A C T}

Proper identification of wild mushrooms is important to study their biodiversity and ecological role. The discovery of new medicinal mushroom species will lead to their exploitation as an industry. No research work has been done about medicinal mushrooms in Murree hills in the past. Keeping in view the importance of Ganoderma species, the present studies were carried out to determine the distribution and prevalence of Ganoderma species in Murree hills on different host plants. In all, eight species of Ganoderma were identified from Murree hills of Pakistan. Cedrus deodara and Eucalyptus citriodora were found to be the most susceptible hosts of Ganoderma species. The identified species were Ganoderma praelongum, G. chalceum (Eucalyptus citriodora), G. applanatum (Abies pindro), G. curtisii, G. multicornum (Cedrus deodara) G. lipsiense (Acacia arabica), G. multiplicatum (Pinus logifolia) and G. boninense (Morus alba). These identified species were non-mushroom and belonged to Phylum Basidiomycota. Variations were observed among different morphological and cultural properties. The color of the pileus surface was found light to dark brown and one species showed white to creamish color. The maximum length and thickness of pileus was found to be $32 \mathrm{~cm}$ and $10 \mathrm{~cm}$ respectively. Majority of Ganoderma specimens were lateral, central, stipitate, dimidiate and sessile. Among cultural characteristics, colonies of the Ganoderma species possessed brown color and some were white to creamish. Colonies were circular and smooth to slimy. Most of the species produced the hyphal system trimetic which had the generative and sketal hyphae. Most spores were brown ellipsoid and oval shape. The maximum spore index was 2.5. Maximum tube size of $1 \mathrm{~cm}$ and minimum tube size $2 \mathrm{~mm}$ were recorded. Pale brown cystidia with thin walls were seen from the germinating cystidia.

Corresponding Author: Fakhar-ud-Din

Email:fakhar178@gmail.com

(C) 2019 EScience Press. All rights reserved.

\section{INTRODUCTION}

Ganoderma species belong to the kingdom Fungi, the division Basidiomycota, the class Homobasidiomycetes, the order Aphyllophorales, the family Poleporaceae
(Ganodermataceae) and the genus Ganoderma. Commonly known as a wood decaying fungus, it causes white rot of a wide variety of trees and can be described as a phytopathogenic fungus (Chang, 1999). Ganoderma 
spp. are considered as medicinal fungi and over 250 Ganoderma spp. have been reported worldwide with most of them from the tropics. Ganoderma spp. are used in folk medicine to cure various diseases such as hypertension, hepatitis, hypercholesterolemia, gastric cancer and many others. Due to its ability to cure many different diseases it received different names like "Elixir of life", "Food of Gods", "Mushroom of the Universe" (Wasson, 1986).

Several strains of Ganoderma spp. are commercially cultivated for the preparation of health tablets or drinks, tonics and sedative drugs widely in Taiwan. Therefore, Ganoderma spp. have received a wide interest for studies ranging from identification, phylogenetic relationship to the content of natural products and their biological activities. Ganoderma has been known in Japan, China and other countries as a food and raw material for the development of drugs. It is a shelf like mushroom that grows on dead and dying trees, the fruiting body of Ganoderma is employed medicinally. Among the different colors and shapes of the fruiting bodies, the red variety is mostly used and commercially cultivated (Steyaert, 1980).

G. lucidum, a complex known in Chinese as Lingzhi, the word lingzhi, in Chinese, means "herb of spiritual potency" and has also been described as "mushroom of immortality" has been considered a symbol of good fortune and prosperity. Lingzhi may possess anti-tumor, immunomodulatory and immunotherapeutic activities, supported by studies on polysaccharides, terpenes, and other bioactive compounds isolated from fruiting bodies and mycelia of this fungus. It has also been found to inhibit platelet aggregation, and to lower blood pressure, cholesterol and blood sugar (Willard, 1990).

Ganoderma species are not classified as edible mushrooms, as the fruiting bodies are stipitate, dimidiate, or reniform and rarely sub orbicular. They are thick, corky, and tough and do not have the fleshy texture characteristics of true edible mushrooms such as common button mushroom. Several types of Ganoderma products are available in the market including, ground fruiting bodies or mycelium processed into capsule or tablet form or tea, Ganoderma beer and Ganoderma hair tonic (Jong and Birmingham, 1992).

Fungi from the family Ganodermataceae are classified as such as they have many tiny holes on the underside of fruiting bodies, which are pores that contain the reproductive spores. They have woody or leathery feel and the presence of these pores are obvious characteristics that distinguish polypores from other common type of mushroom. They degrade the wood over time and produce a fruiting body (or conk) on the surface of wood. Ganoderma species are among those fungi that can thrive under hot and humid conditions and are usually found in subtropical and tropical region (Moncalvo and Ryvarden, 1998).

As early as 800 years ago in the Yuan Dynasty (1280-1368 A.D) Ganoderma lucidum has been represented in painting, carving, furniture, carpet design, jewelry, perfumes bottles and many more creative artworks. According to the two famous Chinese herbal medical books, Shen Nong Ben Cao Jing and Ben Cao Gang Mu by Li Shi-Zhen there were six known Linghzi species in China at that time (Wasser and Weis, 1999). The G. lucidium complex is composed of species with annual fruiting bodies having a yellow to reddish laccate cuticle and an upper layer that is smooth and grooved. The surface is sometimes covered with brownish spore powder. Bracket fungi of the genus Ganoderma are known by mycologists for the crust-like upper surfaces of their fruit bodies, which in all species, such as $G$. pfeifferi and $G$. resinaceum, have a varnished appearance. Arborists and managers of plantation crops know them collectively as a cause of decay in a very wide range of tree species all over the world (Flood et al., 2000).

Proper identification of wild mushrooms is important to study their biodiversity and ecological role. The discovery of new medicinal mushroom species will lead to their exploitation as an industry. No research work has been done about medicinal mushrooms in Murree hills in the past instead of the fact that there is enormous amount of medicinal herbs and trees in those areas. Keeping in view the importance of Ganoderma species, following studies were carried out to determine the distribution and prevalence of Ganoderma species in Murree hills on different host plants. The Ganoderma species were also identified on the basis of morphological and cultural characteristics.

\section{MATERIALS AND METHODS}

Study areas: The studies on the distribution of Ganoderma spp. were conducted in five randomly selected union councils of Murree i.e. Ghora Gali, Charhan, Darya Gali, Sehr Bagla and Murree Urban. The morphological studies were carried out in the Department of Plant Pathology, Pir Mehr Ali Shah Arid Agriculture University, Rawalpindi, Pakistan. 
Collection of specimens: A total of eight fresh fruiting bodies of Ganoderma specimens were collected from different host trees in the Murree hills from spring to monsoon (March to June, 2011). The specimens of Ganoderma were collected from living infected and dead trees of Ghora Gali, Charhan, Darya Gali, Sehr Bagla, and Murree Urban. The samples were collected on its vegetative stage and sorted accordingly. The location/site and substrate on which Ganoderma grew were recorded. Photographs of Ganoderma spp. were taken in their natural habitat to preserve their morphological characters. Specimens were cut out from the trunks of trees by sharp razor with care to avoid damage to the stipe and pileus, and soil was removed by washing with water. Field notes on the macro characters and habit were noted. The collected specimens were individually wrapped, brought to the laboratory and dried in an oven at a temperature of $35^{\circ} \mathrm{C}$. Information about habit, habitat substratum colors and locality were recorded in the field. The specimens were labeled, placed in envelops or airdried. The polythene bags containing the samples were well labeled for easy identification. The identification was done with the help of available literature (Adaskaveg and Gilbertson, 1986; Bakshi, 1971; Gottlieb and Wright, 1999; Ryvarden, 1995, 2000; Steyaert, 1972, 1980).

Morphological characters: Observations on different morphological characters i.e. pileus or cap size, pileus shape, margins, texture, attachment patterns, persistence and surface patterns, stipe: with or without stipe or directly attached to the trunk were recorded.

Collection of basidiospores: Spores were collected from the fruiting bodies in the field by suspending a square Perspex plate covered with clean paper, $1-2 \mathrm{~cm}$ from the surface of the pores. The entire fruit body and suspended plate was then covered with clean paper to minimize airborne contamination.

Preparation of media: Potato dextrose agar (PDA) was prepared by using starch $20 \mathrm{~g}$, agar $20 \mathrm{~g}$, dextrose $20 \mathrm{~g}$ and water to make volume of 1 liter. The medium was sterilized in autoclave at 15 psi for 20 minutes and transferred in the slants or Petri plates for isolation and multiplication of Ganoderma specimens.

Single spore isolations: Spores obtained from fruiting bodies were suspended in a drop of distilled water and streaked onto water agar soon after collection. Streaked plates were incubated at $30^{\circ} \mathrm{C}$ and after germination (1-4 days) single spores were transferred to PDA with the aid of a stereomicroscope at $50 \times$ under dark field illumination. All the cultures were incubated at $30^{\circ} \mathrm{C}$ in the dark for 3-4 days.

Microscopic examination: Basidiospores obtained from spore prints of each specimen were examined under microscope by mounting in a drop of sterile water or Lactophenol drop. Measurement of basidiospores was carried out at $640 \times$ magnification using an eyepiece reticule calibrated with a stage micrometer. The length and width of basidiospores from each of the eight specimens were measured in this way. Spore index was calculated as:

$$
\text { Spore index }=\frac{\text { Length }}{\text { Width }}
$$

Preservation of specimens: The collected specimens were preserved in appropriate preservatives (formaldehyde or alcohol) in the refrigerator at $4^{\circ} \mathrm{C}$ until further processing. Usually $10 \%$ of formalin is used to preserve different specimens of Ganoderma spp. in bottles. Transformation of culture: Fruiting bodies were cut into tiny pieces by using sharp razor and soaked in $0.5 \%$ sodium hypochlorite solution for 2 minutes, washed three times with sterilized water, dried and transferred to PDA Petri plates with minute amount of streptomycin sulphate, and were incubated at $30^{\circ} \mathrm{C}$ for seven days. Inoculums were taken from the slope part of the sample, transfer of material was done under aseptic conditions.

Isolation of Ganoderma mycelium: Isolation of mycelium was made from the basidiomata. Small pieces of basidiomata ( $4 \mathrm{~mm} \times 4 \mathrm{~mm} \times 5 \mathrm{~mm}$ ) were cut and surface sterilized with $5 \%$ sodium hypochlorite for 3 minutes, $0.1 \% \mathrm{HgCl}_{2}$ for 1 minute, and $2 \%$ sodium hypochloride for 2 minutes, blotted dry and plated on PDA with streptomycin sulphate in Petri dishes and were incubated at $30^{\circ} \mathrm{C}$ for seven days. Visible mycelia grown from the pieces of basidiomata were sub-cultured on fresh PDA medium in Petri plates.

Cultural study of Ganoderma spp.: Cultural characteristics such as hyphae, growth pattern, colony color, mycelial color, spore shape, basidia, basidiospore, cystidia and mycelium structure of the specimens were identified.

\section{RESULTS AND DISCUSSION}

Distribution of Ganoderma species: In all, eight species of Ganoderma were identified from the research areas. Cedrus deodara and Eucalyptus citriodora were found to be the most susceptible hosts of Ganoderma species (Table 1).C. deodara was found to be the most susceptible and showed high incidence of infection causing threat to the plantation. The species are well distributed except for 
species G. boninense, G. multiplicatum and G. lipsiense which are restricted to specific locations. The overall counts of valid species described by various authors from Pakistan are G. multiplicatum, G. applanatum, $G$. resinaceum, G. lucidum, and G. philipp. Bilgrami et al. (1991) reported G. annulare, G. adspermum and G. australe from India but all these species are the synonym of G. austal (Moncalvo and Ryvarden, 1998). Murrill (1996) rejected the synonymy of $G$. praelongum with $G$. resinaceum and continued as separate species. Ryvarden (2000) separated G. resinaceum as species with dimitic hyphal system, continuing the synonymy.

Table 1. Hosts of Ganoderma species in Murree.

\begin{tabular}{lcc}
\hline Species & Host tree & Collection site \\
\hline G. praelongum & Eucalyptus citriodora & Ghora Gali \\
G. chalceum & Eucalyptus citriodora & Ghora Gali \\
G. applanatum & Abies pindrow & Charhan \\
G. curtisii & Cedrus deodara & Charhan \\
G. lipsiense & Acacia arabica & Darya Gali \\
G. multiplicatum & Pinus logifolia & Darya Gali \\
G. multicornum & Cedrus deodara & Sehr Bagla \\
G. boninense & Morus alba & Murree Urban \\
\hline
\end{tabular}

The present study accepts the argument of Gottlieb and Wright (1999) since the specimens showed variations in their characters. G. praelongum was reported by Steyaert (1980) from India but was not confirmed due to insufficient material. Bakshi (1971) reported G. ahmadii from India; both these names continued and were accepted by Moncalvo and Ryvarden (1998) but were not observed in the present study. G. lucidum was considered as invalid name by Moncalvo and Ryvarden (1998) but latter Ryvarden (2000) separated the same species under dimitic hyphal system. Similarly $G$. perzonatum was considered as synonym of $G$. cupreum, G. chalceum and $G$. purvulum (Moncalvo and Ryvarden, 1998), but latter these species (G. chalceum and G. perzonatum) were separated under the dimitic hyphal system (Ryvarden, 2000). G. multicornum, was described as new species by Ryvarden (2000) with dimitic hyphal system and with only type locality. The present study reports a new locality for these species from Murree. Understanding the taxonomic status of Ganoderma in Pakistan, it is confirmed that to date five valid species have been reported from Pakistan of which four species viz. $G$. lucidum, G. applanatum, G. philippi, G. multiplicatum, $G$. resinaceum were reported in the present study. Four species viz. G. multicornum, G. chalceum, G. perzonatum, $G$. lipsiense were reported for the first time from Pakistan as shown in Table 1. Thus, there is an urgent need to examine all materials deposited in herbaria, under the genus Ganoderma. The work facilitates in understanding species diversity of Ganoderma from Murree, Pakistan.

Morphological characterization: Eight Ganoderma species were identified on the basis of morphological and cultural characteristics. The ecological data of Ganoderma species are given in Table 2. The identified species are non-mushroom and fall under Phylum Basidiomycota (Figures 1-8). Following morphological characteristics were considered for the identification of Ganoderma species.

Table 2. Ecological data of Ganoderma species.

\begin{tabular}{llll}
\hline Species & Habitat & Growth type & Forest type \\
\hline G. praelongum & Living tree & Solitary & Coniferous \\
G. chalceum & Living tree & Colony & Coniferous \\
G. applanatum & Dead wood logs & Scattered & Broad leaves \\
G. curtisii & Dead wood logs & Scattered & Mixed \\
G. lipsiense & Wood logs & Colony & Mixed \\
G. multiplicatum & Dry tree & Solitary & Coniferous \\
G. multicornum & Dead trunk & Scattered & Mixed \\
G. boninense & Living tree & Colony & Coniferous \\
\hline
\end{tabular}




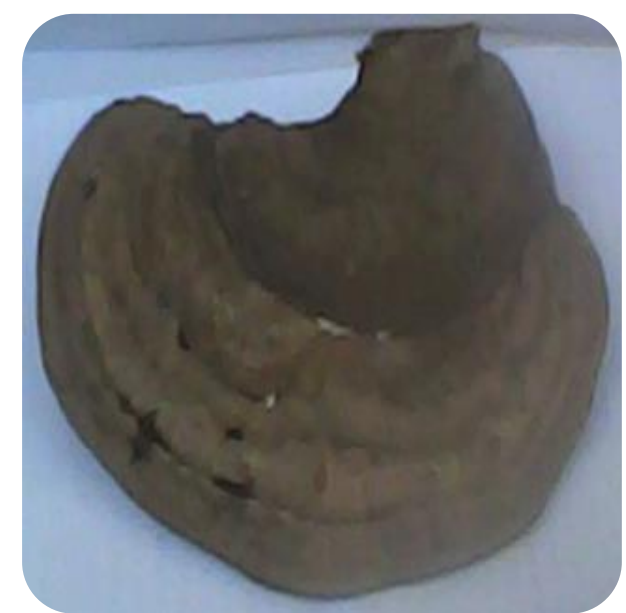

Figure 1. Ganoderma praelongum

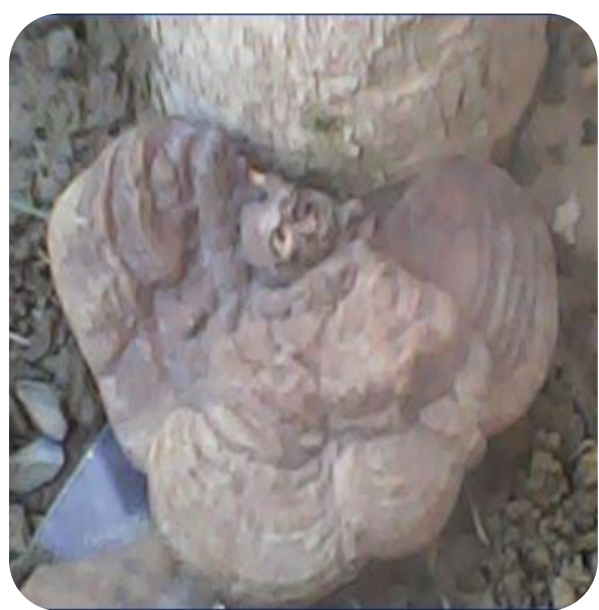

Figure 3. Ganoderma applanatum.

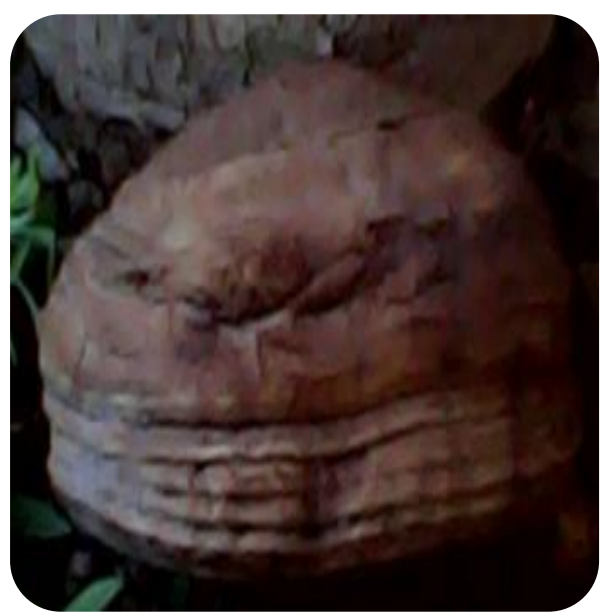

Figure 5. Ganoderma lipsiense.

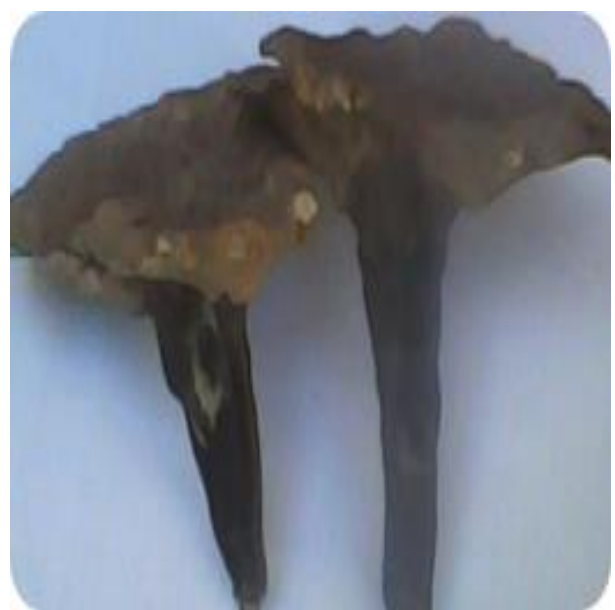

Figure 2. Ganoderma chalceum.

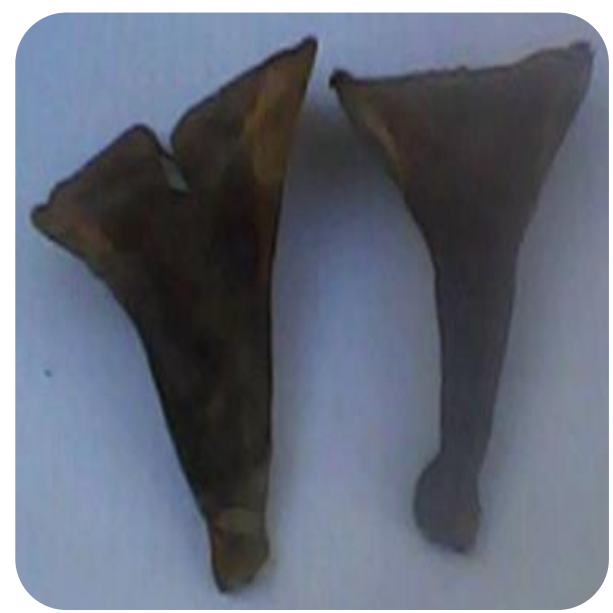

Figure 4. Ganoderma curtisii.

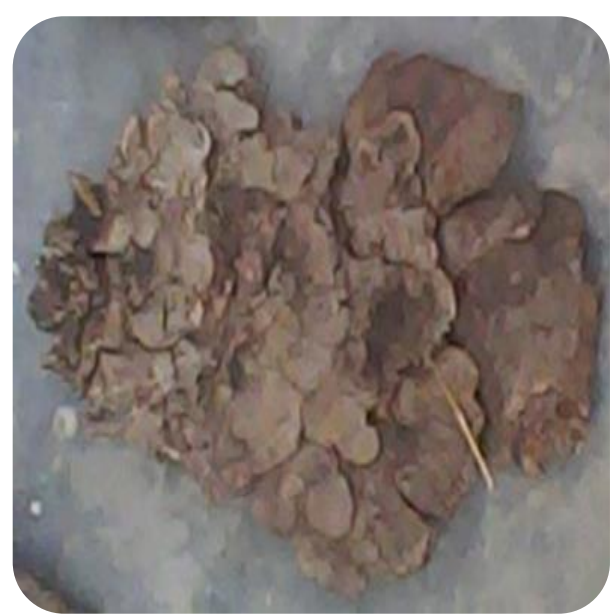

Figure 6. Ganoderma multiplicatum. 


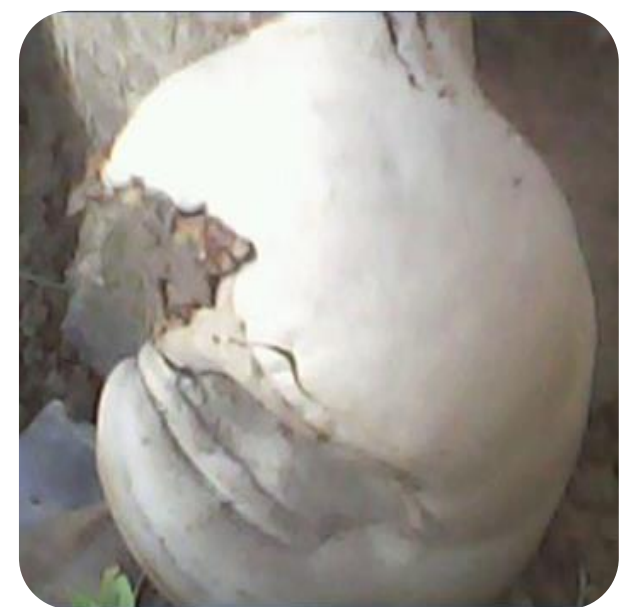

Figure 7. Ganoderma multicornum.

Phenotypic evaluation: Morphological characteristics i.e. pileus surface color, pileus size, pileus shape, attachment patterns of pileus, stipe texture, surface patterns, persistence and margins of pileus were recorded for all the eight Ganoderma species and phenotypically diversities were assessed. The data have been summarized in (Table 3-10).

Pileus surface color: Variations in pileus surface color were noted by observing whether the pileus surface color is light brown, dark brown, dull brown and creamish. Data pertaining to pileus surface color

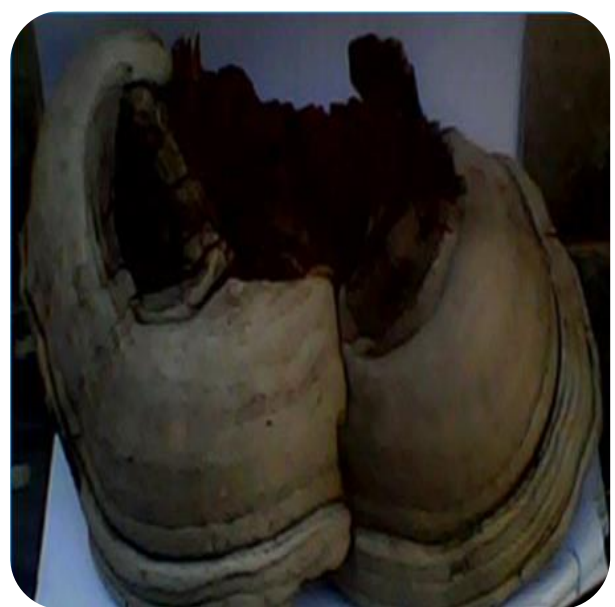

Figure 8. Ganoderma boninense.

(Table 3-10) showed that only G. multicornum and $G$. boninense showed white to creamish upper surface and all other specimens possessed light and dark brown upper surface. There was least diversity among these specimens phenotypically based on pileus surface color.

Pileus size: Data presented in Table 3-10 showed that, pileus size in the eight specimens varied greatly. Maximum length of pileus i.e. $32 \mathrm{~cm}$ and $10 \mathrm{~cm}$ thick was attained by $G$. boninense and minimum of $6 \mathrm{~cm}$ length and $1 \mathrm{~cm}$ thick was recorded by $G$. curtisii.

Table 3. Morphological characters of Ganoderma praelongum.

\begin{tabular}{lll}
\hline & Characteristics & Description \\
\hline A & Pileus surface color & $\begin{array}{l}\text { Upper surface glaberous, sulcate, laccate, bay to brownish brown spore appearing } \\
\text { dusty. At mature stages dark brown with white edges, lower surface smooth and } \\
\text { dark brown }\end{array}$ \\
B & Pileus Size & $9 \mathrm{~cm}$ across, front length up to margins $6 \mathrm{~cm}$ and in the centre $3 \mathrm{~cm}$ thick \\
C & Pileus Shape & Orbicular dimidiate to flabelliform, rarely umbonate to stipitate \\
D & Margins & Smooth, 6 to $7 \mathrm{~mm}$ thin, sterile, cream to ochraceous, acute to sulcate, rarely blunt \\
E & Attachment patterns of pileus & Lateral \\
F & Texture & Corky and flesh \\
G & Surface patterns & 4 deep concentric zones \\
H & Persistence & Perennial with annual growth \\
I & Stipe & No stipe directly attached to the host tree \\
\hline
\end{tabular}

Pileus shape and margins of pileus: Basidiomata examined generally conformed to the holotype but were variable in shape and habit. Data presented in Tables 3-10 showed that the majority of Ganoderma specimens were stipitate or dimidiate and generally had finely (concentrically) grooved surfaces with either acute, rounded or incurved margins only. Table
9 showed that pileus shape of G. multicornum was conical and sessile. There is great variation among the pileus margins. Data showed (Table 3-10), that majority of the specimens were waved, rounded and hard but the Table 3 and 9 showed that G. praelongum and $G$. multicornum were smooth and soft but the surface and margin of the pileus are rough. 
Table 4. Morphological characters of Ganoderma chalceum.

\begin{tabular}{|c|c|c|}
\hline & Characteristics & Description \\
\hline $\bar{A}$ & Pileus surface color & $\begin{array}{l}\text { Upper surface reddish brown, highly sulcate, brown spore } \\
\text { appearing dusty at mature stages dark brown with white }\end{array}$ \\
\hline B & Pileus Size & $8 \mathrm{~cm}$ across, bredth near margins was $2 \mathrm{~cm}$ and in the centre $2 \mathrm{~cm}$ was thick \\
\hline $\mathrm{C}$ & Pileus Shape & Laccate, acute to sulcate, rarely blunt \\
\hline $\mathrm{D}$ & Margins & $\begin{array}{l}\text { Waved and somewhat smooth, } 2 \text { to } 3 \mathrm{~mm} \text { thick, with crust margin hard, acute, } \\
\text { creamish yellow }\end{array}$ \\
\hline $\mathrm{E}$ & \multicolumn{2}{|c|}{ Attachment patterns of pileus Centeral } \\
\hline $\mathrm{F}$ & Texture & Leathery and flesh \\
\hline G & Surface patterns & Shallow waved with $1-3$ concetric zones \\
\hline $\mathrm{H}$ & Persistence & Perennial with annual growth \\
\hline I & Stipe & Stipe length $7-8 \mathrm{~cm}$ \\
\hline
\end{tabular}

Table 5. Morphological characters of Ganoderma applanatum.

\begin{tabular}{|c|c|c|}
\hline & Characteristics & Description \\
\hline $\bar{A}$ & Pileus surface color & $\begin{array}{l}\text { Upper surface pale grey to dark brown, crustose with concentric zonation, } \\
\text { covered with layer of chocolate, brown spore appearing dusty, below surface } \\
\text { smooth and dark brown spore appearing dusty }\end{array}$ \\
\hline B & Pileus Size & $9 \mathrm{~cm}$ across, breth near margins was $3 \mathrm{~cm}$ and in the centre $5 \mathrm{~cm}$ was thick \\
\hline $\mathrm{C}$ & Pileus Shap & Woody to corky, applanate or shelf like \\
\hline $\mathrm{D}$ & Margins & Waved, 6 to $7 \mathrm{~mm}$ thick, sterile, rounded, turning brown on drying \\
\hline E & Attachment patterns of pileus & Sessile \\
\hline $\mathrm{F}$ & Texture & Leathery and flesh \\
\hline G & Surface patterns & 6-7 deep concentric zones \\
\hline $\mathrm{H}$ & Persistence & Perennial with annual growth \\
\hline I & Stipe & Directly attached to the trunk \\
\hline
\end{tabular}

Table 6. Morphological characters of Ganoderma curtisii.

\begin{tabular}{lll}
\hline & Characteristics & Description \\
\hline A & Pileus surface color & $\begin{array}{l}\text { Upper surface dull brown, milky coffee near the margin, concentrically sulcate, } \\
\text { below surface smooth and dark brown spore appearing dusty }\end{array}$ \\
B & Pileus Size & 6 cm across, front length up to margins was $3 \mathrm{~cm}$ and in the centre $1 \mathrm{~cm}$ was thick \\
C & Pileus Shap & Woody to corky, applanate or plane, shelf like \\
D & Margins & Margin thin lobate, sterile, brown at old age $1 \mathrm{~mm}$ thick \\
E & Attachment patterns of pileus & Lateral \\
F & Texture & Soft and flesh \\
G & Surface patterns & Smooth \\
H & Persistence & Perennial with annual growth \\
I & Stipe & Stipe length $4-5 \mathrm{~cm}, 6 \mathrm{~mm}$ thick \\
\hline
\end{tabular}

Attachment and surface patterns of pileus: Data pertaining to attachment and surface patterns of pileus showed significant differences among the specimens. The pileus of the normal fruit body is laterally attached to the stipe, but eccentric and central. Majority of the specimens were lateral but Table 4 and 5 showed central and sessile. The result were in agreement with those of Schwalb
(1988). The surface of the pileus was rough, waved and had many narrow concentric zones but the Table 6, 7 and 9 showed the smooth.

Texture, persistence and stipe: Data presented in Tables 3-10 showed that there were great similarities among the Ganoderma specimens. Most specimens' texture was corky and flesh. All the specimens were perennial with annual 
growth. There was less difference among the stipe attachment of all the specimens which were directly attached to the trunk except Table 4 and 6 . The maximum stipe length of 7-8 cm was observed in case of $G$. chalceum. Although variations existed in the morphological characteristics of basidiomata from the five union councils of Murree, the overall morphology of the basidiomata falls Table 7. Morphological characters of Ganoderma lipsiense.

\begin{tabular}{lll}
\hline & Characteristics & Description \\
\hline A & Pileus surface color & Upper Surface slightly zonate, pulverulent glabrous, tuberous, crust, rigid, up to 1 \\
& & mm thick, reddish grey or cinnamon. Lower surface smooth and dark brown \\
B & Pileus Size & $7 \mathrm{~cm}$ across, front length $5 \mathrm{~cm}$. margins was $3 \mathrm{~cm}$ and in the centre $4 \mathrm{~cm}$ was thick \\
C & Pileus Shap & Orbicular dimidiate to flabelliform, rarely umbonate to stipitate \\
D & Margins & Margin hard, obtuse, slightly thick and lobate, cinnamon to grayish white or slightly \\
& & yellowish \\
E & Attachment patterns of pileus Lateral \\
F & Texture & Corky and flesh \\
G & Surface patterns & Smooth \\
H & Persistence & Perennial with annual growth \\
I & Stipe & Directly attached to the trunk \\
\hline
\end{tabular}

Table 8. Morphological characters of Ganoderma multiplicatum.

\begin{tabular}{|c|c|c|}
\hline & Characteristics & Description \\
\hline A & Pileus surface color & $\begin{array}{l}\text { Upper surface concentrically sulcate, brown of chestnut, lower surface smooth } \\
\text { and dark brown }\end{array}$ \\
\hline B & Pileus Size & $\begin{array}{l}12 \mathrm{~cm} \text { across, front length up to margins was } 9 \mathrm{~cm} \text { and in the centre } 1 \mathrm{~cm} \text { was } \\
\text { thick }\end{array}$ \\
\hline $\mathrm{C}$ & Pileus Shap & Pileate, stipitate, dimidiate \\
\hline $\mathrm{D}$ & Margins & Waved, 8 to $9 \mathrm{~mm}$ thin, sterile, brown to ochraceous, acute to sulcate, rarely blunt \\
\hline E & Attachment patterns of pileus & Lateral \\
\hline $\mathrm{F}$ & Texture & Corky and flesh \\
\hline G & Surface patterns & Shallow waved \\
\hline $\mathrm{H}$ & Persistence & Perennial with annual growth \\
\hline I & Stipe & Directly attached to the trunk \\
\hline
\end{tabular}

Table 9. Morphological characters of Ganoderma multicornum.

\begin{tabular}{|c|c|c|}
\hline & Characteristics & Description \\
\hline A & Pileus surface color & $\begin{array}{l}\text { Upper Surface slightly creamish white, below surface light brown, sulcate and } \\
\text { zonate }\end{array}$ \\
\hline B & Pileus Size & $\begin{array}{l}15 \mathrm{~cm} \text { across, front length up to margins was } 8 \mathrm{~cm} \text { and in the centre } 10 \mathrm{~cm} \text { was } \\
\text { thick }\end{array}$ \\
\hline $\mathrm{C}$ & Pileus Shap & Conical, sessile \\
\hline $\mathrm{D}$ & Margins & Smooth, regular, soft, obtuse, creamish white sterile, 2 to $2.5 \mathrm{~cm}$ thick \\
\hline E & Attachment patterns of pileus & Lateral \\
\hline $\mathrm{F}$ & Texture & Corky and brittle \\
\hline G & Surface patterns & Smooth \\
\hline $\mathrm{H}$ & Persistence & Perennial with annual growth \\
\hline I & Stipe & Directly attached to the trunk \\
\hline
\end{tabular}


Table 10. Morphological characters of Ganoderma boninense.

\begin{tabular}{|c|c|c|}
\hline & Characteristics & Description \\
\hline$\overline{\mathrm{A}}$ & Pileus surface color & $\begin{array}{l}\text { Upper Surface slightly zonate, pulverulent glabrous, white to creamish, lower } \\
\text { surface smooth and light brown }\end{array}$ \\
\hline B & Pileus Size & $32 \mathrm{~cm}$ across, front length up to margin $15 \mathrm{~cm}$, and in the centre $10 \mathrm{~cm}$ was thick \\
\hline $\mathrm{C}$ & Pileus Shape & Stipitate or dimidiate and generally had finely (concentrically) grooved surfaces \\
\hline $\mathrm{D}$ & Margins & Rounded or incurved margins hard, thick and lobate, cinnamon \\
\hline E & Attachment patterns of pileus & Lateral \\
\hline $\mathrm{F}$ & Texture & Corky and flesh \\
\hline G & Surface patterns & Smooth and somewhat 3 waved \\
\hline $\mathrm{H}$ & Persistence & Perennial with annual growth \\
\hline I & Stipe & Directly attached to the trunk \\
\hline
\end{tabular}

Cultural characterization: Due to the variability of Ganoderma species on the hosts, it is evident that identification must be supported with cultural data. Cultural studies were therefore, conducted to investigate the colony color, hyphal system, mycelial color, cutis, tube size, context layer, spore index, spore shape and cystidia shape. The results as found in this study are as follows.

Colony color and hyphal system: Colonies of the Ganoderma species grew very slowly. Table 11-14 showed that the majority of the specimens possessed brown color and some white to creamish. Colonies were circular, smooth to slimy, finely radiating with regular margins. There was no production of conidiomata on the host material. Shape tends to be variable, but the size, color and the ornamentation of the hyphal system were consistent and there were less difference found, most species produced the hyphal system trimetic which had the generative and sketal hyphae as shown in Table 1114. Mycelium appeared 'stringy' in growth. There was some production of conidiomata on the host material.

Spore production: Basidiomata maturity were marked by spore production when the fruiting body reached a constant size. Spores were strongly ejected from the pore layer and fell all over the basidiomata surface. The spore deposits were light brown and powder form, they were also found on the upper surface of the basidiomata, giving it a velvety golden appearance. Spores discharge were light in the first three days, becoming very heavy from the forth. Most deposited spores were ellipsoid and oval shape. The maximum spore index of 2.5 was recorded for G. multiplicatum and minimum spore index of 1.66 was found in G. chalceum. There were great similarities among the spore print color of all Ganoderma specimens as shown in Table 11-14.

Table 11. Cultural Characteristics of G. praelongum and G. chalceum.

\begin{tabular}{lll}
\hline Characters & G. praelongum & G. chalceum \\
\hline Colony color & White to pale yellow & Light brown \\
Hyphal system & Trimitic & Dimitic \\
Mycelial color & Yellowish brown & Brown \\
Cutis & Diverticulate & Claviform \\
Generative hyphae & $3.3-4.1 \mu \mathrm{m}$ & $3.5 \mu \mathrm{m}$ \\
Skeletal hyphae & $5 \mu \mathrm{m}$ & $7.5 \mu \mathrm{m}$ \\
Binding hyphae & $6.6 \mu \mathrm{m}$ & $7.5 \mu \mathrm{m}$ \\
Tube size & $2 \mathrm{~mm}$ & $13 \mathrm{~mm}$ \\
Context layer & $4 \mathrm{~mm}$ & $15 \mathrm{~mm}$ \\
Spore index & 1.77 & 1.60 \\
Spore shape & Ellipsoid & Ovoid \\
Cystidia shape & Gloeocystidia & Macrocystidia \\
\hline
\end{tabular}

Tube size, cutis shape and context layer evaluation: Data pertaining to tube size (Table 11-14) showed differences among specimens. Maximum tube size was $1 \mathrm{~cm}$ and minimum tube size was $2 \mathrm{~mm}$. Most cutis shape was 
diverticulate but some showed the claviform. The maximum context layer of $30 \mathrm{~mm}$ and minimum of $4 \mathrm{~mm}$ were recorded. Cystidia shape evaluation: Fungus produced other yeast-like characteristics. Cystidia were produced by budding directly from hyphae. Pale brown cystidia with thin walls were seen from the germinating cystidia or directly from the hyphae. There were great variations among cystidial shapes as shown in Table 11-14.

Table 12. Cultural Characteristics of the G. applanatum and G. curtisii.

\begin{tabular}{lll}
\hline Characters & G. applanatum & G. curtisii \\
\hline Colony color & Light grey & Yellowish brown \\
Hyphal system & Trimitic & Trimitic \\
Mycelial color & Pale yellow & Yellowish brown \\
Cutis & Trichodermis & Claviform \\
Generative hyphae & $3.3-4.1 \mu \mathrm{m}$ & $2.5 \mu \mathrm{m}$ \\
Skeletal hyphae & 5.8 to $6.6 \mu \mathrm{m}$ & $5 \mu \mathrm{m}$ \\
Binding hyphae & $7.5 \mu \mathrm{m}$ & $3.3 \mu \mathrm{m}$ \\
Tube size & $8 \mathrm{~mm}$ & $10 \mathrm{~mm}$ \\
Context layer & $6 \mathrm{~mm}$ & $10 \mathrm{~mm}$ \\
Spore index & 2.16 & 1.87 \\
Spore shape & Oval & Obpyriform \\
Cystidia shape & Leptocystidia & Echinidia \\
\hline
\end{tabular}

Table 13. Cultural Characteristics of G. lipsiense and G. multiplicatum.

\begin{tabular}{lll}
\hline Characters & G. lipsiense & G. multiplicatum \\
\hline Colony color & Creamish white & Brown \\
Hyphal system & Trimitic & Dimitic \\
Mycelial color & Brown & Yellowish \\
Cutis & Trichodermis & Diverticulate \\
Generative hyphae & $3.3 \mu \mathrm{m}$ & $3.8 \mu \mathrm{m}$ \\
Skeletal hyphae & $5 \mu \mathrm{m}$ & $5.8-7.5 \mu \mathrm{m}$ \\
Binding hyphae & $5 \mu \mathrm{m}$ & $3.4 \mu \mathrm{m}$ \\
Tube size & $13 \mathrm{~mm}$ & $3 \mathrm{~mm}$ \\
Context layer & $30 \mathrm{~mm}$ & $5 \mathrm{~mm}$ \\
Spore index & 1.91 & 2.5 \\
Spore shape & Ellipsoid & Ellipsoid \\
Cystidia shape & Macrocystidia & Chrysocystidia \\
\hline Table 14: Cultural Characteristics of $G$. multicornum and $G$. boninense. & \\
\hline Characters & G. multicornum & G. boninense \\
\hline Colony color & Brown & White \\
Hyphal system & Dimitic & Dimitic \\
Mycelial color & Light brown & Pale Orange \\
Cutis & Diverticulate & Diverticulate \\
Generative hyphae & $3-5 \mu \mathrm{m}$ & $4.1 \mu \mathrm{m}$ \\
Skeletal hyphae & $15 \mu \mathrm{m}$ & $5-6.6 \mu \mathrm{m}$ \\
Binding hyphae & $5 \mu \mathrm{m}$ & $3.4 \mu \mathrm{m}$ \\
Tube size & $5 \mathrm{~mm}$ & $1 \mathrm{~cm}$ \\
Context layer & $13 \mathrm{~mm}$ & $5 \mathrm{~mm}$ \\
Spore index & 2 & 1.82 \\
Spore shape & Obviate & Reniform \\
Cystidia shape & Leptocystidia & Macrocystidia \\
\hline
\end{tabular}


Basidiospore dimensions of Ganoderma species: The eight species of Ganoderma also showed variations in basidiospore dimensions i.e. spore color, spore length, spore shape and spore index as shown in Table 15. This finding may hold further repercussions for the identification and publication of other Ganoderma species. Without cultures, it appears difficult to accurately identify a Ganoderma spp. or distinguish whether variation is caused by environmental factors or is due to collections representing different taxa.

Table 15. Basidiospore dimensions of Ganoderma species.

\begin{tabular}{lllll}
\hline Species & Spore color & Spore Length & Spore shape & Spore index \\
\hline G. praelongum & Reddish brown & $8.0 \times 4.5$ & Ellipsoid & 1.77 \\
G. chalceum & Reddish brown & $7.4 \times 4.6$ & Ovoid & 1.60 \\
G. applanatum & Pale yellow & $7.8 \times 3.6$ & Oval & 2.16 \\
G. curtisii & Brown & $9.0 \times 4.8$ & Opyriform & 1.87 \\
G. lipsiense & Brown & $9.2 \times 4.3$ & Ellipsoid & 1.91 \\
G. multiplicatum & Brown & $8.5 \times 3.4$ & Ellipsoid & 2.5 \\
G. multicornum & Brown & $6.8 \times 3.4$ & Obviate & 2 \\
G. boninense & Reddish brown & $9.5 \times 5.2$ & Reniform & 1.82 \\
\hline
\end{tabular}

Author Contributions: FD and TM planned and designed the studies, FD conducted surveys, collected samples and identified the species, TM supervised the research work, FD wrote the manuscript and TM edited it.

Conflict of interest: The authors declare no conflict of interest.

\section{REFERENCES}

Adaskaveg, J.E., Gilbertson, R.L., 1986. Cultural studies and genetics of sexuality Ganoderma lucidum and Ganoderma tsugae in relation to the taxonomy of the Ganoderma lucidum complex. Mycologia 78, 694-705.

Adaskaveg, J.E., Gilbertson, R.L., 1989. Cultural studies of North American Species in Ganoderma lucidum complex with comparisons to G. lucidum and $G$. tsugae. Mycological Research 92, 182-191.

Bakshi, B.K., 1971. The Polyporaceae (On Trees and Timber). Indian Council of Agriculture Research New Delhi, 58-62.

Bilgrami, K.S., Jamaluddin, S., Rizvi, M.A., 1991. Fungi of India, 2nd ed. Today and Tomorrows Printers and Publishers, New Delhi.

Chang, S.T., 1999. Global impact of edible and medicinal mushroom on human welfare in the 21st century, nongreen revolution. International Journal of Medicinal Mushrooms 1, 1-7.

Flood, J., Bridge, P.D., Holderness, M., 2000. Ganoderma diseases of perennial crops. CABI Bioscience Publishing. UK.

Gottlieb, A.M., Wright, J.E., 1999. Taxonomy of Ganoderma from South America subgenus Ganoderma.
Mycological Research 103, 661-673.

Ho, Y.W., Nawawi, A., 1985. Ganoderma boninense from basal stem rot of oil palm (Elaies guineensis) in Peninsular Malaysia. Pertanika 8, 425-428.

Jong, S.C., Birmingham, J.M., 1992. Medicinal Bnefits of Mushroom Ganoderma. Advances in Applied Microbiology 37, 104-134.

Moncalvo, J.M., Ryvarden, L., 1998. A nomenclatural study of the. Ganodermataceae Synopsis Fungorum, Oslo, Norway.

Murrill, W.M., 1996. The Polyporaceae of North America. The genus Ganoderma. Bulletin of the Torrey Botanical Club 29, 599-608.

Ryvarden, L., 1995. Can we trust morphology in Ganoderma? , Fifth International Mycological Congress, pp. 19-24.

Ryvarden, L., 2000. Studies in neotropical polypores 2: A preliminary key to neotropical species of Ganoderma with a laccate pileus. Mycologia 92, 180-191.

Schwalb, M.N., 1988. Genetics and Morphogenesis in the Basidiomycetes. Academic Press, New York.

Steyaert, R.L., 1972. Species of Ganoderma and related genera mainly of the Bogor and Leiden herbaria. Persoonia 7, 55-118.

Steyaert, R.L., 1980. Study of some Ganoderma species. Bulletin du Jardin botanique national de Belgique 50, 135-186.

Wasser, S.P., Weis, A.L., 1999. General description of the most important medicinal higher Basidiomycetes mushrooms. International Journal of Medicinal 
Mushrooms 1, 351-370.

Wasson, R.G., 1986. Soma Divine Mushroom of Immortality. Harcourt, Brace and World, Incorporation, New York.

Willard, T., 1990. Reishi mushroom. Herb of spiritual potency and medical wonder. Sylvan Press, Seattle, WA.

Zhao, J.D., 1989. The Ganodermataceae in China. Bibliotheca Mycological Journal 12, 112-145. 